\title{
Educational Model for Cross-Generational Collaboration
}

\author{
Rafal Glębocki \\ Faculty of Science \\ and Technology \\ Jan Dlugosz University \\ in Czestochowa \\ Częstochowa, Poland \\ r.glebocki@ujd.edu.pl \\ Joanna Górna \\ Faculty of Social Sciences \\ Jan Dlugosz University \\ in Czestochowa \\ Częstochowa, Poland \\ j.gorna@ujd.edu.pl
}

\author{
Alina Gil \\ Faculty of Science \\ and Technology \\ Jan Dlugosz University \\ in Czestochowa \\ Częstochowa, Poland \\ a.gil@ujd.edu.pl
}

\author{
Monika Kowalczyk-Gnyp \\ Faculty of Social Sciences \\ Jan Dlugosz University \\ in Czestochowa \\ Częstochowa, Poland \\ m.kowalczyk-gnyp@ujd.edu.pl
}

\author{
Urszula Nowacka \\ Faculty of Science \\ and Technology \\ Jan Dlugosz University \\ in Czestochowa \\ Częstochowa, Poland \\ u.nowacka@ujd.edu.pl
}

\begin{abstract}
The paper's considerations relate to an Erasmus ${ }^{+}$project called Generation: Smart. Social Competences Transmedia Bridge To Cultivate A New Culture For Cross-Generational Collaboration. The consortium agreed that due to profound changes in the contemporary Network Societies, people of various generations have to collaborate. However, it is a complex issue due to the divergent life purposes of different aged people. Thus, the project's targeted group, i.e., educators who support adult learners, should be equipped with an educational model that constitutes a solution to this situation. The assumption was that such a model is to include social competences enabling the processes of cross-generational collaboration. Information technology transmedia blend is supposed to bridge the gap between generations. In the paper, we present an overlook of the research that focuses on developing such a framework model. The research features triangulation, which means the analysis of both quantitative and qualitative data. It is structured in three parts. The first one deals with the statistical embracement of the social environment in which the cross-generational collaboration occurs in project partner countries. It is quantitative desk research that utilizes Eurostat information. It is worth pointing out that the research is in statu nascendi. In two consecutive parts, the researchers want to acknowledge the cross-generational collaboration in working life and everyday life. Here, the survey method and the questionnaire interview technique serve as the qualitative research method. Two research groups are to be reached: entrepreneurs and the Third Age Universities' participants. The results of the above two stages will be known after the publication of this paper.
\end{abstract}

Nonetheless, a proto-model recommendation is presented along with educational conclusions on how to use the model. The concept is based on the prior partners' analysis and design work.

Keywords - cross-generational collaboration, educational model, social competences, transmedia blend.

\section{INTRODUCTION}

The future depends on connectivity. Not only is it important technologically (connected devices - the Internet of Things: gathering data, e.g., to power the Artificial Intelligence algorithms), but it directly also touches people. The context of the research described in the paper focuses on the cross-generational gap that features contemporary Network Societies [1]. The term "network society" defines the stage in the development of societies in the modern world. In the network society, information is subject to a wide flow - with the use of IT and, above all, the Internet. Nowadays, due to, e.g., profound technological and demographic changes, people of different generations have to collaborate. Life and professional activities in the contemporary world demand to overcome challenges and bridge the gaps between generations. Educators who support adult learners originating from different age groups need an educational model to bridge the cross-generational gap. Such a model should be a flexible structure that can be easily updated. It can comprise a part of social competences and another part

Online ISSN 2256-070X

https://doi.org/10.17770/etr2021vol2.6606 (C) 2021 Rafał Gtębocki, Alina Gil, Urszula Nowacka, Joanna Górna, Monika Kowalczyk-Gnyp Published by Rezekne Academy of Technologies. This is an open access article under the Creative Commons Attribution 4.0 International License. 
dealing with information technology as well as innovative pedagogy. Transmedia approach - of or relating to more than one form of media ${ }^{1}$ - can constitute a solution aiming at embracing and implementing a new culture for crossgenerational collaboration [2]. It can be cultivated in two main domains: working life and everyday life. The former deals with the present and future needs of work environments. The latter one includes, among others, senior citizens, and it is strongly connected with social responsibility in the aspect of making a better world.

The model for cross-generational collaboration (the CGC Model) is supposed to be the outcome of an Erasmus+ project titled "Generation: Smart. Social Competences Transmedia Bridge To Cultivate A New Culture For Cross-Generational Collaboration" (GSmart). More information about the project can be found on the web page https://www.generationsmart.eu/ .

\section{MATERIALS AND METHODS}

The main material connected with the research is the model itself. A model - a construction that is a simplified image of a selected fragment of reality; a formalized approach to a theory or situation in which it generates specific data. Models as descriptions are almost always partial or incomplete because they concern only selected characteristics [3]. The process of the CGC Model designing and constructing follows such a procedure of construction and verification:

1. The preliminary structure of the model (proto-model) has been designed (Fig. 1).

2. The model is subject to testing via an educational process of Transnational Training Sessions that are supposed to be conducted during the GSmart project.

3. The construction of the final design of this model is proposed.

The validity of the above procedure was confirmed by S. Libow Martinez and G. Stager [4]. They promote the term 'tinkering' in the sense of taking action to improve learning processes that arise from experience, experimentation and discovery. They also introduce the term 'constructing' to draw conclusions from experience and combine intuition - thinking and reflection - with formal aspects. It enables measurement and understanding as well as an explanation of the consequences of actions.

Following the concept of model development originally proposed by S. Libow Martinez and G. Stager, as well as by D. Leclercq and M. Poumayit [5]. It is assumed that the concept of designing and constructing an educational model consists of three stages:

1. Idea stage - refers to initial thoughts concerning a given issue. It may include phases: feedback from others, brainstorming, resource analysis, goal setting, model outline, impact prediction, developing an action sequence diagram - a dynamic procedure of events.

2. Creation stage - the initiation of the action occurs. It may include phases of creating, experimenting, constructing and deconstructing, testing, observing the impact, documenting the process, looking for weaker elements, and reacting to them accordingly.

3. Development stage - a properly designed and constructed model should correspond to the initial assumptions of the specialists who created it. The model can be applied in educational practice. Simultaneously, the model can - and even should - be improved by considering the changing conditions of time, place, people, concept development, or needs and requirements for the education of a particular group of learners.

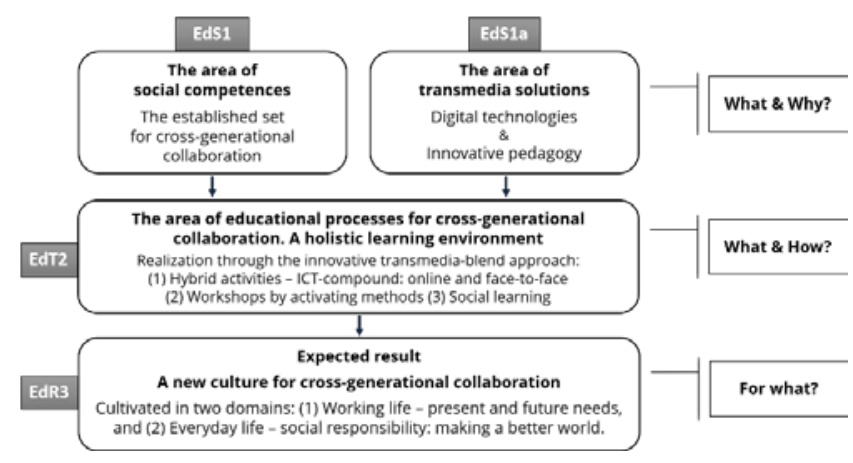

Fig. 1. Proposal of an educational model for cross-generational collaboration. The CGC Model - preliminary blueprint (proto-model)

EdS1 - the first stage of implementation of the CGC Model - the level of educational strategy. It refers to an established set of social competences.

In the project, it is assumed that to participate in the Network Societies actively, the members of such societies should be strategically educated (1) on social competences that support the development of the meta-competence (a competence that is self-referential; it is at a higher level and beyond others) - the ability for cross-generational collaboration, and (2) through digital Technology and innovative pedagogy - the transmedia-blend approach [2].

By cross-generational competence, we understand the ability of different-age people to go partners. It can be both in working life and everyday life domains. For contemporary societies, this issue is of paramount significance.

According to ESCOpedia (European Skills, Competences, Qualifications and Occupations (ESCO)), "[...] competence means the proven ability to use knowledge, skills and personal, social and/or methodological abilities, in work or study situations and professional and personal development" [6]. Whereas the term 'skill' refers mainly to methods and instruments, "[...] 
competence is broader and refers to the ability of a person - facing new situations and unforeseen challenges - to use and apply knowledge and skills in an independent and selfdirected way" [6].

Transversal knowledge, skills and competences must also be taken into account [7]. They are "relevant to $a$ broad range of occupations and economic sectors. They are often referred to as core skills, basic skills, or soft skills, the cornerstone for the personal development of a person" [8]. Competences are organized in a hierarchical structure - with five headings. One of them is 'social interaction'. It underpins the GSmart project and constitutes the project's core notion regarding competences considerations.

For the sake of the GSmart project, the set of social interaction competences - the social competences - that support cross-generational collaboration has been established based on earlier research [9]. It was conducted in connection with the Erasmus+ project "Intranet: Intrapreneurship net-playbook" (Intranet) [10].

The set of social competences that support the crossgenerational collaboration:

\section{Adaptation,}

2. Barrier-breaking,

3. Conflict resolution,

4. Creativity,

5. Critical thinking

6. Collaboration,

7. Communication,

8. Community building,

9. Cross-generational attitude swap. A competence that includes the following stages: (1) From the point of pre-existing experience, (2) Through building the cross-generational consideration, and (3) To reach the level of understanding of how to bridge the cross-generational gap.

10. Decision making,

11. Empathy - helping others,

12. Experimentation encouragement,

13. ICT - skills, and abilities of the Digital Age,

14. Inspiring,

15. Knowledge-sharing,

16. Leadership responsibility,

17. Motivation,

18. Negotiation,

19. Problem analysis,

20. Problem-solving,
21. Resilience - goal-oriented approach,

22. Social responsibility,

23. Teamwork.

The above set of social competences that bridge the cross-generational gap has been introduced to the public in the research described in the paper.

EdS1a - the first stage of implementation of the CGC Model - the level of educational strategy. It refers to the chosen transmedia solutions.

Hybrid activities - ICT-compound: online and face-toface

Ten interactive tasks supporting the development of cross-generational collaboration through social competences. A derivative of the outcome material of the Erasmus+ Intranet project. From this perspective, the GSmart project will be a continuation of the Intranet project - yet adjusted to other social needs and contexts.

Workshops by activating methods

Five training sessions are delivered in face-to-face mode. Various proven methodologies, e.g., Design Thinking, Lego Serious Play, or gamification elements, will boost cross-generational collaboration through social competences.

\section{Social Learning}

Multiple social learning channels, such as online discussion, audio-video interactions, peer-coaching, or Slack collaborative environment, will foster a mutual understanding by cross-generational social competences [11].

Following the trend of social connectivity that features up-to-date online platforms[12], the mixture of the three foremost forms will be integrated into one holistic, consistent, and coherent framework. Multi-channel communication through the cloud-based systems Edueca (the platform by CIDET (Spain) is the place for the interactive online activities on the cross-generational collaboration through social competences), Google Workspace (the service is supposed to be a collaboration space for both the project partners and the project targeted groups, in the latter case, it will be a significant part of the project transmedia approach) and the Slack collaborative mobile environment will facilitate the integration of the GSmart's teaching and learning forms of the project. This procedure will enable us to constitute a bridge on crossgenerational collaboration by education on and expansion of social competences.

EdT2 - the second stage of the implementation of the CGC Model - the level of educational tactics. It concerns the area of educational processes for crossgenerational collaboration.

Tactically (operationally), it will be done by the application of the innovative transmedia-blend approach within a holistic learning environment. It means that 
the content and teaching and learning methods will combine three earlier mentioned primary forms.

\section{EdR3 - the third stage of the implementation of the} CGC Model - the level of results.

It concerns the expected objective of the model's operation. It is the cultivation - achievement, application, and development - of a new culture ${ }^{2}$ for crossgenerational collaboration in two domains: (A) Working life and (B) Everyday life - social responsibility: making a better world.

By social responsibility, we understand the ability to take the perspective of and empathize with others from different: ages - including seniors, backgrounds, and cultures - social environments, as well as to understand ethical norms for behavior. It is also a usage of creative intelligence in connection with community resources.

In the concept of competence, the term social responsibility has been specified as "[...] the ability to act responsibly, autonomously, and considering values and standards and the effects that can be anticipated for oneself, others, and situations, and also to consciously endure the resulting consequences" 13]. The research reveals a strong connection between social responsibility and the ability to cooperate - collaborate with others [13].

The discussed domain has a lot in common with the term "social intelligence," i.e., "[...] the ability to connect to others deeply and directly, to sense and stimulate reactions and desired interactions" [14] - also by the activities that can benefit senior adult learners. Socially intelligent people can quickly assess the emotions of those around them and adapt their actions accordingly. It should be a key feature for those who need to collaborate crossgenerationally and build relationships of trust. It is important in cross-generational collaboration with larger groups of people and different settings. Such an approach is directed to the notions of social inclusion and the inclusion of senior adult learners.

\section{The CGC Model's Features}

\section{At the meta-level}

\section{A framework construction}

A framework means here a collection of proposed solutions with the possibility of alternation or expansion. It can be done both in the scope of content and processes related to the development of the system functionality.

It means predefining the elements of the structure, content, and procedure of the action - Dynamic Procedure of Events (DPE - described later). Such design will provide stability and, at the same time, flexibility in terms of prospective modifications and improvements of how to use the model. Such an approach ensures the possibility of a selection of social competences and transmedia solutions, as well as alternations in the scope of educational processes - methods and the choice of the educational aim(s).

\section{At the practical level - Learning, Teaching and Training Activities}

\section{Adjustability and validity}

The GCG Model will be adjusted and validated in the training process by the project's targeted groups - during the project's training sessions. The knowledge on how to use the model will be passed to the project's targeted groups. Opinions of the project targeted groups will be used to improve the model assumptions.

\section{Dynamic Procedure of Events}

While maintaining the functional usability and flexibility of the CGC Model, it is possible to indicate the Dynamic Procedure of Events (DPE), which applies to this model. This procedure determines the proper functioning of the model. It has been assumed that the CGC Model aims to achieve a learning process that supports the development of a new culture for cross-generational collaboration.

Level of educational strategy - the definition of: who, what, and why. The stage of model implementation: 1

At the first stage of implementing the CGC Model, a strategic selection of social competences takes place (Fig. 1. EdS1). Educators can develop social competences according to a particular group of learners' needs and expectations - to boost the cross-generational collaboration. It is done by choosing relevant parts of the course implemented for the sake of the project's targeted groups. The parts' activities aim to develop different social competences and - as a result - the meta-competence of cross-generational collaboration.

The education and development of social competences using digital technologies and innovative pedagogy are strategic objectives - sine qua non conditions - of education in the Network Society [15]. For this reason, the first strategic level of implementation of the CGC Model also includes transmedia solutions (Fig. 1. EdS1a). The selection of specific tools has been described earlier. They serve the educational processes at the level of educational tactics -during the second stage of implementation.

The level of educational tactics - the definition of: who, what, and how. The stage of model implementation: 2

At the second stage of implementation of the CGC Model - in the area of educational processes for crossgenerational collaboration - the integration of the area of social competences with the area of transmedia solutions takes place. It is done by implementing and verifying the learning environment (Fig. 1. EdT2). Learning environment - which is a key element as it determines the
${ }^{2}$ Culture - here: (1) development or improvement of the minds by education or training; (2) The set of shared attitudes, values, goals, and practices that characterizes an institution or organization (Webster's definitions: https://www.merriamwebster.com/dictionary/culture [Accessed: Mar. 2, 2020]). 
proper functioning of the CGC model - means here educational cooperation that consists of the following elements:

1. Educators - with whom one learns. In the GSmart project - the project's targeted groups, i.e., educators and other personnel who support adult learners;

2. Learners - who learns. In the GSmart project - adult learners educated on the cross-generational collaboration in working life and/or everyday life domains;

3. Content - what is taught, e.g., social competences to develop the meta-competence of cross-generational collaboration.

4. Methods and activities - how to learn, e.g., following innovative transmedia-blend approach - activating methods of teaching and learning;

5. Space, time, and infrastructure - learners learn where, when, and using what, e.g., digital Technology, the virtual space, and online [16].

Level of results - definition of: what is the result of the learning process that has been designed and carried out.

The stage of model implementation: 3

The third stage of the CGC Model implementation is to achieve the expected result of the educational process (Fig. 1. EdR3). This is done through teaching and learning processes as well as the analysis of the results of the verification (testing) and the use of updated information. The result is a learning environment that includes a range of processes that foster the development of a new culture for cross-generational collaboration. This new kind of culture can be cultivated in two domains: (1) Working life - present and future needs, and (2) Everyday life social responsibility: making a better world.

In the GSmart project, this scope constitutes elements of educational processes:

Social competences factors defined at the first stage of the implementation of the CGC Model - in the area of social competences;

Digital technologies and innovative pedagogy defined at the first stage of implementation - in the area of transmedia solutions;

Activating teaching and learning methods, i.e., innovative transmedia-blend approach. It comprises three main elements:

1. Hybrid activities - ICT-compound: online and face-toface.

2. Workshops for the project's target groups with the know-how on the cross-generational collaboration education - by activating methods.

3. Social Learning.
Integrating the components mentioned above within the CGC Model aims to achieve an innovative educational framework for cross-generational collaboration. It can constitute the theoretical and methodological basis for the a course created in the GSmart project for the sake of the project's targeted groups.

The methods that deal with the CGC Model are strongly connected with the research. It's main aim is to prepare the best educational offer for the project's targeted groups to enable them their work on cross-generational collaboration.

The primary desk research was conducted during the processes of the GSmart project proposal elaboration. It included analyzing such sources as books, articles, and reports. Thus, it was a kind of state-of-the-art analysis. We concluded that a consistent and reliable update on the cross-generational collaboration issue is highly recommended.

Therefore, the actual project's research collects and analyzes statistical information and notions of the empirical kind. It features the so-called triangulation [17]. Statistics and Social Sciences refer to the analysis of both quantitative and qualitative data to obtain more accurate research results.

As omne trinum perfectum, the research is divided into three parts:

Part 1: Cross-generational collaboration in the social environment. Eurostat data are used to embrace the notion of cross-generational collaboration. It is supposed to be a big picture of the issue in question in the partner countries. It is quantitative desk research that characterizes the population and labor market situation in the GSmart partner countries. It features the state and structure of the population by sex, age groups, the population aged $65+$, the old-age dependency ratio and population projections to 2030, as well as the labor force participation rate by sex, age 15-64, education level, the employment rate for the 1564 age group by sex and education level, and statistics on the unemployment rate for the 15-74 age group by sex and education level.

The statistics were obtained from Eurostat, and the available information (as of February 24, 2021) covers the periods from 2018 to 2020 (as of January 1), while the Labour Force Survey (LFS) covers the 3rd quarter of 2019 and 2020.

Part 2: Cross-generational collaboration in working life Working life indicates connections with professional activities. The GSmart research takes the perspective of entrepreneurs and managers of different ages [18]. The qualitative research assumes a selection of the research group. Participants should originate from the working life environment, i.e., entrepreneurs and managers of different ages and groups in companies, institutions, associations, and foundations. The research group should consist of not less than 30 representatives in each partner country. Here, we intend to embrace the difficulties in cross-generational 
collaboration and ways of dealing with it. This part of the research is directed to managers of companies, institutions, and associations or foundations. The research is conducted by an online survey.

Part 3: Cross-generational collaboration in everyday life. Everyday life designates natural and ordinary world activities. It is experienced and treated as a foundation for all forms of standardized and targeted actions. The GSmart research takes the perspective of seniors [19]. The qualitative research is also conducted by an online survey. It aims to describe the cross-generational collaboration in everyday life from the perspective of seniors who originate from the selected Third Age Universities (TAU) in partner countries. The research assumes a selection of the research group. The research group consists of not less than 30 seniors - TAU(s) participants from each country.

\section{RESULTS AND DISCUSSION}

As stated in the introduction, the research team is in the process of research implementation. It started in January 2021 and is about to finish in July the same year. A complete discussion will be possible once a report with the research outcomes is published on the project's web page. However, it has already been possible to present the outset summary of the first part of the research. It is the following:

In 2020, compared to the same period in 2018, population growth was recorded in all partner countries except Poland. Populations in partner countries are predominantly male, except for Turkey where there is a higher percentage of women $50.2 \%$ (Fig. 2).

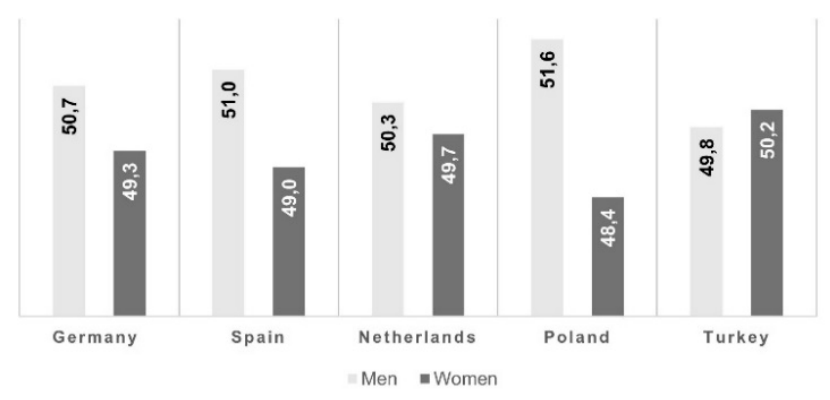

Fig. 2. January 2020 - percentage of men and women in partner countries (data in \%)

In 2020, one in three people in the partner country populations were aged 25-49. In the age group 50-64, there was one in four German, one in five Spanish, Dutch and Polish citizens, and one in seven Turkish citizens. Every seventh citizen of Spain and Poland was aged 65-79, every eighth citizen of Germany and the Netherlands, and every fourteenth citizen of Turkey (7.3\%). One in five citizens of Germany, Spain, the Netherlands, Poland, and one in eleven of Turkey were aged 65 or older. Every third citizen of Turkey was aged 0-24 (every sixth citizen aged 15-24), every fourth citizen of Germany, Spain, the Netherlands, and Poland (every tenth citizen aged 15-64 and every eighth citizen of the Netherlands).
In 2020, compared to the same period in 2018, populations in the partner states were experiencing an increase in the percentage of people aged 65 and older.

The old-age dependency ratio increases in all partner countries, with the highest value in 2020 in Germany at $33.7 \%$ and the lowest in Turkey at $13.4 \%$.

In the forecast to 2030 for the European partner countries (no Eurostat data for Turkey), only Poland is projected to decrease population. The most significant population increase is projected for the Netherlands and the smallest for Germany.

In 2020, the highest labor force participation rate among partner countries was recorded in the Netherlands at $81.1 \%$ and the lowest in Turkey at $56.3 \%$. The labor force participation rate was highest among people with tertiary education regardless of the partner country and ranged from $77.7 \%$ in Turkey to $90.4 \%$ in the Netherlands. It had the lowest values among people with less than primary, primary, and lower secondary education from $27.1 \%$ in Poland to $65.0 \%$ in the Netherlands. In 2020, compared to the same period in 2019, the labor force participation rate fell in Germany (-0.2 pp, i.e., percentage point), Spain (-1.2 pp) and Turkey (- $3.2 \mathrm{pp})$, in the Netherlands, it remained at the same level, and in Poland, it increased by $0.3 \mathrm{pp}$.

The employment rate in the partner countries in 2020 was the highest in the Netherlands, $77.6 \%$, the lowest in Turkey, 48.8\%, and the highest among people with higher education regardless of the partner country, from $66.8 \%$ Turkey to $88.2 \%$ in Poland. The lowest value of this indicator was among those with less than primary, primary, and lower secondary education, from $42.5 \%$ in Turkey to $59.8 \%$ in the Netherlands. The employment rate in 2020 compared to the same period in 2019 decreased in almost all partner countries except Poland, where an increase of 0.1 pp was recorded. Its largest decrease was observed in Spain by 2.7 pp.

According to the LFS (LSF), the unemployment rate in the third quarter of 2020 was highest in Spain and Turkey at $16.3 \%$ and $13.2 \%$, respectively, and lowest in Poland at $3.3 \%$. Compared to the same period in 2019, the unemployment rate decreased only in Turkey by $0.8 \mathrm{pp}$ and increased in Spain by $2.4 \mathrm{pp}$.

\section{CONCLUSIONS}

A new post-pandemic reality will probably shed yet new light on the processes of cross-generational collaboration. Both the CGC Model described in this paper, and the research can become a decent reference for the parties that need to embrace the issue in question. 


\section{REFERENCES}

[1]. W. Gogołek, Network communication. Conditions, categories and paradoxes [Komunikacja sieciowa. Uwarunkowania, kategorie i paradoksy], Warsaw: ASPRA-JR Publishing House, 2010, pp. 17-31.

[2].H. Jenkins, "Transmedia. What?", Nov. 2016. [Online] Available: https://immerse.news/transmedia-what15edf6b61daa [Accessed: March 9, 2021].

[3]. J. Apanowicz, Methodological determinants of scientific work [Metodologiczne uwarunkowania pracy naukowej], Warsaw: Difin Publishing House, 2005.

[4]. S. Libow Martinez and G. Stager, Invent To Learn: Making, Tinkering, and Engineering in the Classroom. Torrance, CA: Constructing Modern Knowledge Press, 2013.

[5].D. Leclercq and M. Poumay, "The 8 Learning Events ModelAnd Its Principles", 2005. [Online] Available: http://www.labset.net/media/prod/8LEM.pdf [Accessed: January 22, 2021].

[6]. “Competence”, 2020. [Online] Available: https://ec.europa.eu/esco/portal/escopedia/Competence [Accessed: Jan. 22, 2021].

[7]. "Catalogue of Transversal Competences Key for Employability." [Online] Available: http://www.keystart2work.eu/images/docs/o2catalogue/O2_Catalogue_EN.pdf [Accessed: January 22, 2021].

[8]. "Transversal knowledge, skills and competences," 2020. [Online] Available: https://ec.europa.eu/esco/portal/escopedia/Transversal_kno wledge_44_skills_and_competences [Accessed: Jan. 22, 2021].

[9].H. Saiz-Sanchez, P. Escuder-Mollon and S. Luna-Ojeda, "Online activities for acquiring soft skills and transversal competences in organisations and teams; the erasmus+ intranet project," presented on 11th International Conference on Education and New Learning Technologies, Palma, Spain, 1-3 July, 2019. [Online] Available: EDULEARN19 Proceedings, doi: 10.21125/edulearn.2019.2364, http://lib.uib.kz/edulearn19/files/papers/2364.pdf [Accessed: January 22, 2021].

[10].Erasmus+ Project KA 204 2018-1-ES01-KA204-050708. A transnational project of Hungary (TREBAG), Netherlands (SEALS), Poland (JDU), Slovenia (CPU), and Spain (CIDET - Coordinator). [Online] Available: http://intranet.org/ [Accessed: Mar. 2, 2020].
[11].eLearning Industry, Free eBook: "Social Learning In The Workplace," $2019 . \quad$ [Online] Available: https://elearningindustry.com/social-learning-in-theworkplace-free-ebook [Accessed: Mar. 2, 2020].

[12].J. van Dijck, T. Poell and M. de Waal, The Platform Society: Public Values in a Connective World. New York: Oxford University Press, 2018.

[13].A. Frey, B.J. Ertelt and J.J. Ruppert, "Diagnosis of Social, Methodical, and Personal Competencies in Vocational Training and Job Analysis: A German Perspective," European Questionnaire for Job Analysis (EQJA), Theoretical and Methodological Bases, Series: Polish Studies in Economics, A. Biela, Ed. Berlin, Bern, Bruxelles, New York, Oxford, Warsaw, Wien: Peter Lang Publishing House, 2018, pp. 101-127.

[14].A. Davies, D. Fidler and M. Gorbis, "Future Work Skills 2020", Institute for the Future for University of Phoenix Research Institute, 2011. [Online] Available: http://www.iftf.org/uploads/media/SR-

1382A_UPRI_future_work_skills_sm.pdf [Accessed: March 2, 2020].

[15].R. Głębocki, “A model of education and a new culture of learning”, Pedagogika. Studia i rozprawy, vol. XXVIII, Czestochowa: JDU Publishing House, 2019, pp. 27-35. [Online] Available: http://212.87.236.17:8080/Content/6069/3_Glebocki_Peda gogika_28.pdf [Accessed: Jan. 21, 2021].

[16]."The Nature of Learning. Using Research to Inspire Practice", Centre for Educational Research and Innovations, H. Dumont, D. Istance and F. Benavides, Ed. Paris: OECD iLibrary, 2010.

[17].S. Glen: "Triangulation in Research Statistics and Social Sciences," StatisticsHowTo.com: Elementary Statistics for the rest of us!, 2017. [Online] Available: https://www.statisticshowto.com/triangulation [Accessed: January 8, 2021].

[18]. "Duration of working life - statistics," Eurostat, May 2020. [Online]. Available: https://ec.europa.eu/eurostat/statisticsexplained/index.php/Duration_of_working_life_-_statistics [Accessed: Jan. 8, 2021].

[19].B. Mateja-Jaworska and M. Zawodna-Stephan, Research On Everyday Life in Poland [Badania życia codziennego w Polsce], Poznań: Adam Mickiewicz University Publishing House, 2019. 